\title{
Velocidades das coordenadas obtidas por Posicionamento por Ponto Preciso: um modelo considerando coordenadas horizontais e altura elipsoidal
}

\author{
Velocities of the coordinates obtained by Precise Point Positioning: a model considering \\ horizontal coordinates and ellipsoid height
}

\author{
José Luiz Fay de Azambuja ${ }^{1}$ \\ Marcelo Tomio Matsuoka ${ }^{1,2}$ \\ ${ }^{1}$ Programa de Pós-Graduação em Sensoriamento Remoto - UFRGS. Av. Bento Gonçalves, 9500, Campus do Vale. Cep \\ 91501-970. Porto Alegre, RS, Brasil. \\ ${ }^{2}$ Laboratório de Topografia e Geodésia (LTGEO), Instituto de Geografia, UFU - Rod. LMG 746, km 01, s/n, bloco 1, \\ Campus Monte Carmelo. Cep 38500-000. Monte Carmelo, MG, Brasil. \\ jlfazambuja@gmail.com, tomiomatsuoka@gmail.com
}

Recebido em 22/08/2015 - Aceito em 28/06/2016

Received on 22/08/2015 - Accepted on 28/06/2016

\begin{abstract}
RESUMO - Um método de posicionamento por GNSS que vem se popularizando nos últimos anos é o Posicionamento por Ponto Preciso (PPP). O PPP refere-se ao método de posicionamento que se utiliza de dados de apenas um receptor e requer, fundamentalmente, o uso de efemérides e correções dos relógios dos satélites precisos. Neste artigo utilizou-se o serviço canadense CSRS-PPP no processamento de um longo período de dados superior a onze anos coletados em noventa e cinco das estações da RBMC. A análise das velocidades obtidas a partir das respectivas séries temporais referentes às coordenadas diárias estimadas pelo CSRS-PPP mostraram resultados com pequenas discrepâncias quando comparadas com os valores oficiais adotados para as estações analisadas. Entretanto, constatou-se na maioria das estações um comportamento sazonal referente à altura elipsoidal que impossibilita a adoção de velocidades lineares de translação no sistema cartesiano X, Y e Z. Como solução, propõe-se a adoção das velocidades de deslocamento calculadas para coordenadas planas, particularmente as coordenadas UTM, sendo a altura elipsoidal corrigida através de modelos estabelecidos em função da variação sazonal registrada em cada uma das estações da RBMC.
\end{abstract}

Palavras-chave: GPS/GNSS; Posicionamento por Ponto Preciso; Velocidades de Translação da Placa Sul Americana; Variação Anual da Altura Elipsoidal

\begin{abstract}
Precise Point Positioning (PPP) is a positioning method for GNSS that has become more popular in recent years. PPP refers to the positioning method that utilizes data from a single receiver and requires the use of ephemeris and corrections from precise satellite clocks. In this work we have used the Canadian CSRS-PPP service to process data periods longer than eleven years collected from 95 RBMC stations. The speed analysis obtained from time series relating to daily coordinates estimated by CSRS-PPP showed results with small discrepancies when compared with the official values adopted for the analyzed stations. However, most of the stations have shown a seasonal behavior related to the ellipsoidal height that prevents the adoption of linear translation speeds in the $\mathrm{X}, \mathrm{Y}$ and $\mathrm{Z}$ Cartesian system. As a solution, we propose the adoption of the calculated forward speeds for planar coordinates, especially UTM coordinates, and the ellipsoid height corrected by models set according to seasonal variation recorded in each of the RBMC stations.
\end{abstract}

Keywords: GPS/GNSS; Positioning by Precise Point; Translation speeds of the South American Plate; Annual variation of Ellipsoidal Height

\section{INTRODUÇÃO}

Muito embora teorias elaboradas há cerca de um século atrás preconizavam o deslocamento das placas tectônicas e, por consequência, a variação das coordenadas dos pontos situados na superfície da Terra, pouca importância era dada a este aspecto, haja visto as grandes dificuldades para aferir suas magnitudes, associadas às precisões a ela relacionadas. 
$\mathrm{O}$ advento de técnicas modernas espaciais, que somente se tornaram possíveis pela conquista do espaço envolvendo o lançamento de satélites e a exploração lunar, e o advento da eletrônica e da computação, tornaram possível o desenvolvimento do sistema GPS e outras técnicas descritas ao longo deste artigo, que facilitaram a determinação dos deslocamentos das Placas Tectônicas formadoras da superfície terrestre.

Neste artigo é analisada a potencialidade do método de Posicionamento por Ponto Preciso (PPP) ser utilizado na mensuração desses deslocamentos, visando transformar as coordenadas de um ponto determinadas para uma certa época em coordenadas relativas a uma época distinta, normalmente estabelecida como base de um sistema de referência - no caso brasileiro o SIRGAS2000.

Nos estudos relacionados à movimentação da Terra, sejam referentes à sua rotação e translação, sejam em relação à movimentação das placas tectônicas, o GNSS tem se mostrado como um dos mais importantes instrumentos utilizados (DING, 2005).

Uma de suas principais características que resultam na sua importância, refere-se ao fato de que utiliza-se de elementos situados fora do planeta (satélites) para determinar alterações ocorridas na Terra, o que torna muito mais confiáveis as conclusões obtidas.

Nos últimos anos, o método denominado PPP (Posicionamento por Ponto Preciso) tem ganhando cada vez mais popularidade. Muito embora seja usado com sucesso desde a década passada (ex: ZUMBERGE et al., 1996), o PPP se limitava basicamente aos usuários que possuíam aplicativos computacionais de cunho científico, o que, de certa forma, o afastava da grande maioria dos usuários. Alguns trabalhos brasileiros já foram realizados empregando o método PPP, como por exemplo, MONICO (2008), PEREZ et al. (2003), ABREU e FONSECA Jr (2005).

Dentre os serviços on-line de processamento de PPP, encontra-se o fornecido pelo NRCan (Natural Resource Canada), denominado CSRS-PPP (Canadian Spatial Reference System - Precise Point Positioning) (NRCan, 2009; LAHAYE et al., 2008), utilizado no processamento de dados coletados nas estações da RBMC (Rede Brasileira de Monitoramento Contínuo), para verificar a potencialidade deste método em aplicações geodésicas, particularmente na determinação da velocidade de deslocamento da Placa Tectônica da América do Sul. Particularmente no Brasil, onde o IBGE implantou e mantém a RBMC (Rede Brasileira de Monitoramento Contínuo), que é constituída por uma estrutura nacional com as mesmas características da rede IGS (International GNSS Service), estando em plena atividade desde agosto de 1997 (FORTES, 1997), foi possível ao autor realizar uma análise da variação temporal das coordenadas de todas as estações no período de 2002 a 2013, com o objetivo de estudar o deslocamento da Placa Tectônica da América do Sul, particularmente de sua porção localizada em território brasileiro, visando determinar as suas velocidades de deslocamento no sistema cartesiano $\mathrm{X}, \mathrm{Y}$ e $\mathrm{Z}$, bem como no plano horizontal (planimétrico) em território brasileiro e analisar o comportamento de seus deslocamentos verticais, mediante a utilização do processamento de dados GPS.

O conhecimento das velocidades de deslocamento da Placa Tectônica da América do Sul em território brasileiro, reveste-se de grande importância na medida em que o PPP fornece resultados referentes à época da coleta de dados e, na maioria das vezes, é necessário compatibilizar estes resultados relacionando-os a outra época - no caso brasileiro à época 2000.4 considerada como referência do SIRGAS2000, para que se tenha conhecimento de como e porque estes movimentos ocorrem e tenhamos condições de calcular, com bastante precisão, as coordenadas dos pontos situados na superfície terrestre e ter condições de prever suas variações no futuro.

Ao final do artigo será proposto o estabelecimento de um modelo para a determinação das velocidades de deslocamento da Placa Tectônica da América do Sul, particularmente no que se refere ao território brasileiro, considerando tanto o movimento horizontal quanto o vertical.

\section{FUNDAMENTAÇÃO TEÓRICA E METODOLO- GIA}

O Posicionamento por Ponto Preciso é um método que se baseia em observações não diferenciadas, utilizando as efemérides precisas das órbitas dos satélites.

As efemérides precisas estão associadas tanto às órbitas dos satélites propriamente ditas, quanto aos erros dos relógios dos respectivos satélites.

Estes produtos podem ser utilizados no processamento de observações de pseudodistâncias, fase da onda portadora, ou ambas, as quais podem ter sido coletadas por receptores de uma ou duas frequências (ou até mais).

Nesse caso, tem-se o método de PPP, o qual geralmente se utiliza receptor de dupla frequência, envolvendo o uso das duas observáveis nas duas portadoras. Este método apresenta grande potencialidade de ser utilizado em aplicações de geodinâmica, com significativas vantagens sobre o processamento de redes GNSS, onde há um elevado dispêndio computacional.

Segundo LEICK (2004), o PPP refere-se ao posicionamento com GNSS utilizando dados de apenas um receptor, com precisão em torno do centímetro quando se considera o modo estático e um longo período de coleta de dados - até a precisão da ordem de alguns decímetros, quando utilizado o modo cinemático. Nesses casos, para atingir este nível de qualidade, deve-se considerar como observável no processamento a combinação linear livre da ionosfera para a fase da onda portadora e/ou código (LEICK, 2004; HOFMANNWELLENHOF et al., 2008), o que obviamente implica no uso de receptor de dupla frequência.

É importante salientar que o PPP também tem sido realizado com dados de receptores de simples frequência, implicando, porém, na obtenção de resultados que apresentam menor precisão. A razão para essa degradação 
na qualidade está na impossibilidade de formar a observável livre da ionosfera. Uma alternativa para minimizar os efeitos da ionosfera no PPP para usuário de receptor de simples frequência é o uso de algum modelo da ionosfera (exemplos: Modelo de Klobuchar; Modelo Global da Ionosfera do IGS).

Um dos requisitos fundamentais do PPP é o uso de efemérides e correções dos relógios dos satélites, ambos com alta precisão (MONICO, 2008 WITCHAYANGKOON, 2000). Essas informações têm sido produzidas e disponibilizadas pelo IGS e centros associados, sem nenhum custo ao usuário final (IGS, 2008).

Visando reduzir a degradação resultante da interpolação, o GSD (Geodetic Survey Division), do NRCan, gera correções dos relógios dos satélites com intervalo de 30 segundos (HÉROUX e KOUBA, 1995) sendo que o JPL também realiza trabalho similar (MONICO, 2008). O IGS produz, desde outubro de 2000 , arquivos com correções dos relógios dos satélites com intervalo de 5 minutos.

A qualidade das coordenadas estimadas no PPP está relacionada principalmente aos erros considerados no processamento dos dados, cuja remoção parcial ou completa dos efeitos é realizada através dos modelos matemáticos (ROSA, 2008).

No caso de serem utilizados receptores de dupla frequência - muito comum no PPP - o erro correspondente à ionosfera é eliminado por meio da combinação linear livre da ionosfera (WUEBBENA et al., 1997), utilizando as observações do código e da fase da onda portadora nas duas frequências.

O objeto a ser posicionado pode estar imóvel, caracterizando o posicionamento estático, ou estar em movimento, caracterizando o Posicionamento por Ponto Preciso Cinemático. No método cinemático, o receptor coleta dados enquanto está se deslocando, permitindo estimar as coordenadas de sua trajetória (MONICO, 2008).

A exemplo dos outros tipos de processamento, o erro do relógio do receptor assim como outros erros, incluindo aquele advindo da refração troposférica, são estimados no ajustamento e os erros dos relógios dos satélites e os das órbitas por eles descritas, são considerados conhecidos.

Cabe registrar ser possível a ocorrência de outros erros, dentre os quais citamos os associados ao multicaminho e à variação do centro de fase da antena, que podem ser removidos da equação livre da ionosfera, desde que sejam tratados adequadamente.

Para Seeber (2003), o multicaminho afeta tanto as observações de fase quanto as do código, embora em magnitude diferente.

Já os efeitos sobre as observações do código $\mathrm{P}$ (militar) normalmente são afetados com uma magnitude duas vezes maior que as observações de fase, podendo alcançar de decímetros a metros.

É sabido que uma das formas de se obter redução nos efeitos do multicaminho se constitui na utilização de antenas tipo choke ring, muito embora seja consenso de que a melhor forma para se evitar este tipo de erro reside na escolha de locais apropriados para realizar o levantamento, evitando superfícies refletoras próximas à antena.

Há também o problema referente à variação do centro de fase da antena que pode ser minimizado através do emprego de antenas calibradas. Segundo MADER (2001), ignorando as variações do centro de fase os erros verticais podem chegar a dez centímetros.

Já Freiberger Jr. (2005) realizou um estudo com o objetivo de investigar métodos de calibração de antenas de receptores GNSS.

Para alcançar alta precisão no posicionamento por ponto, especialmente tratando-se do PPP, esses erros devem ser eliminados ou reduzidos a valores negligenciáveis.

Quanto ao erro devido ao atraso troposférico, o mesmo pode ser separado em duas partes, uma seca e outra úmida, dos quais cerca de noventa por cento são devidos à parte seca, a qual pode ser estimada com precisão próxima a um por cento quando a pressão atmosférica é conhecida. Já com relação à parte úmida, sua modelagem é mais difícil de ser realizada.

Para reduzir a influência dessa fonte de erro no PPP, o atraso zenital troposférico para a parte úmida, associado a uma função de mapeamento, é modelada como um parâmetro a ser estimado junto aos demais parâmetros no ajustamento.

Assim sendo, o ajustamento de observações relativo ao Posicionamento por Ponto Preciso consiste na determinação dos parâmetros correspondentes às três coordenadas da estação rastreada, do erro do relógio do receptor, de um parâmetro correspondente ao atraso zenital troposférico (parte úmida) bem como dos termos de ambiguidades (livre da ionosfera e não inteiros) para tantos quanto forem o número de satélites observados.

Como o PPP geralmente requer dados de receptores de dupla frequência, as equações linearizadas que fazem parte do PPP são a pseudodistância e a fase da onda portadora nas duas frequências.

Quando se utilizam dados de receptores de dupla frequência, tanto de pseudodistância quanto de fase, os modelos matemáticos envolvidos no PPP que descrevem as observáveis depois de realizada a combinação linear livre da ionosfera, são dados por (MONICO, 2008; LEICK, 2004):

$$
\begin{aligned}
& \operatorname{PD}_{\mathrm{r}(\mathrm{IF})}^{\mathrm{s}}=\rho_{\mathrm{r}}^{\mathrm{s}}+\mathrm{c}\left(\mathrm{dt}_{\mathrm{r}}-\mathrm{dt}^{\mathrm{s}}\right)+\mathrm{T}_{\mathrm{r} 0}^{\mathrm{s}}+\mathrm{dT}_{\mathrm{z}} \mathrm{m}(\mathrm{E}) \\
& \varphi_{\mathrm{r}(\mathrm{IF})}^{\mathrm{s}}=\frac{\mathrm{f}_{1}}{\mathrm{c}} \rho_{\mathrm{r}}^{\mathrm{s}}+\mathrm{f}_{1}\left(\mathrm{dt}_{\mathrm{r}}-\mathrm{dt}^{\mathrm{s}}\right)+\mathrm{N}_{\mathrm{IF}}+\frac{\mathrm{f}_{1}}{\mathrm{c}} \mathrm{T}_{\mathrm{r} 0}^{\mathrm{s}}+\frac{\mathrm{f}_{1}}{\mathrm{c}} \mathrm{dT}_{\mathrm{z}} \mathrm{m}(\mathrm{E})
\end{aligned}
$$

onde:

$\mathrm{PD}_{r}^{S}(\mathrm{IF})$ é a pseudodistância resultante da combinação linear livre da ionosfera;

$\boldsymbol{\varphi}_{r}^{S}($ IF) é a fase obtida da combinação linear ion-free;

$\rho_{r}^{s}$ é a distância geométrica entre o centro de fase da antena do satélite e do receptor;

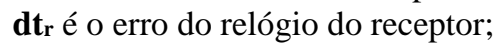

$\mathbf{d t}^{\mathbf{s}}$ é erro do relógio do satélite s;

$\mathbf{N}_{\text {IF }}$ é a ambiguidade da observável ion-free; 
$\mathbf{T}_{\boldsymbol{r}}^{\boldsymbol{S}_{\mathbf{0}}}$ é o atraso troposférico aproximado por algum modelo disponível;

$\mathbf{d T}_{\mathbf{z}}$ é o atraso zenital troposférico residual a ser estimada no modelo;

m(E) é a função de mapeamento em função do ângulo de elevação E do satélite;

c é a velocidade da luz no vácuo;

f 1 é a frequência da observável ion-free (igual a da portadora L1).

No modelo matemático apresentado anteriormente, comparecem somente os erros mais comuns. Observando a equação, pode-se verificar que os parâmetros (incógnitas) a serem estimados envolvem as coordenadas da estação (presentes no termo $\rho_{r}^{S}$ ), o erro do relógio do receptor $\left(\mathrm{dt}_{\mathrm{r}}\right)$, a correção residual da troposfera $\left(\mathrm{dT}_{\mathrm{Z}}\right)$ e o vetor de ambiguidades $\left(\mathrm{N}_{\mathrm{IF}}\right)$.

$\mathrm{O}$ erro do relógio do satélite $\left(\mathrm{dt}^{\mathrm{s}}\right)$ é injuncionado pelo valor disponibilizado pelo IGS ou por qualquer outro centro (exemplo: NRCan, JPL). O valor do atraso troposférico aproximado $\left(\mathrm{T}_{r}^{S_{0}}\right)$ é obtido pelo uso de algum modelo disponível, como por exemplo, o de Hopfield e o Saastamoinen (MONICO, 2008).

Outros erros, como o relacionado ao centro de fase da antena dos satélites e do receptor também devem ser tratados no PPP. Adicionalmente, os erros relacionados a marés terrestres, carga dos oceanos, entre outros, podem também ser levados em conta. Uma descrição detalhada dos erros envolvidos pode ser encontrada em MONICO (2008), LEICK (2004), HOFMANN-WELLENHOF et al., (2008) e WITCHAYANGKOON (2000).

Pode-se observar que há o envolvimento de quatro observáveis para cada um dos satélites visíveis em cada época. As duas observáveis de fase de batimento da onda portadora podem ser combinadas linearmente, reduzindo os efeitos de refração ionosférica.

De forma análoga, é possível realizar este procedimento com as pseudodistâncias do código. A refração troposférica pode ser minimizada utilizando um dos vários modelos existentes em conjunto com alguma técnica de parametrização (MONICO, 2008).

O ponto central desta técnica é a não utilização das efemérides e correções dos relógios dos satélites contidos na mensagem de navegação, as quais estão degradadas pelos efeitos da SA. Desta forma, estes parâmetros devem ser disponibilizados para os usuários por alguma fonte independente.

Atualmente, o IGS produz três tipos de efemérides e correções para o relógio dos satélites, denominadas de efemérides finais (IGS), rápidas (IGR) e ultrarrápidas (IGU). Uma descrição detalhada desses produtos pode ser obtida em MONICO (2008). A maioria desses produtos tem cada um dos elementos disponibilizados (coordenadas X, Y e Z e erro do relógio de cada satélite) em intervalos de 15 minutos, sendo esse intervalo adequado para realizar interpolações das coordenadas dos satélites, mas nem sempre para as correções dos relógios (MONICO, 2008).No que diz respeito à qualidade das efemérides, elas apresentam precisão da ordem de $0,10 \mathrm{~m}$,
0,50 m e 1,00 m para as órbitas IGS, IGR e IGP respectivamente.

As correções para os relógios dos satélites, pelo menos para os produtos IGS, apresentam precisão da ordem de poucos centímetros. face à alta variabilidade devido aos efeitos da SA, o que acarreta uma grande degradação na qualidade das correções interpoladas.

As correções para os relógios dos satélites, em conjunto com as efemérides precisas, podem proporcionar posicionamento por ponto, utilizando apenas pseudodistâncias de uma única época de observação, com precisão da ordem de um metro ou melhor.

No que se refere ao posicionamento por ponto de alta precisão, é imprescindível ter a disposição dados de receptores de dupla frequência, isto é, pseudodistância e fase da onda portadora nas duas portadoras.

Desta forma, a equação pode ser escrita para as pseudodistâncias em L1 e L2. Além disto, duas equações de fase da onda portadora também fazem parte do processamento.

\section{RESULTADO E DISCUSSÕES}

Inicialmente foram coletados os dados disponíveis no sítio do IBGE referentes às noventa e cinco estações componentes da RBMC que estiveram ativas no período de 01/01/2002 a 11/09/2013, totalizando 175.740 arquivos de dados com vinte e quatro horas de coleta, com taxa de 15 segundos, obtendo-se, ao final de todo o processamento uma longa série temporal das coordenadas estimadas para cada dia pelo serviço on-line CSRS-PPP.

$\mathrm{O}$ processamento dos dados pelo CSRS-PPP envolveu como observável básica a combinação linear livre da ionosfera (código e fase), sendo utilizadas efemérides precisas e arquivos de correção dos relógios dos satélites, ambos, produzidos pelo IGS. Adotou-se 15 segundos como o intervalo de estimação e somente observações coletadas com ângulo de elevação igual ou superior a 10 graus foram incluídas.

$\mathrm{O}$ atraso troposférico foi estimado durante o processamento. Também foram aplicadas as correções relacionadas à variação do centro de fase da antena dos satélites e do receptor utilizando informações fornecidas pelo IGS.

A distribuição espacial no final do ano de 2014 das estações componentes da RBMC - de acordo com seu "status", classificadas como ativas (em verde), inativas (em vermelho) e em observação (em amarelo) - estão mostradas na Fig. 1 a seguir. Nota-se uma acentuada concentração de estações nos Estados de São Paulo e sul de Minas Gerais enquanto que na região amazônica a distribuição é menos densificada. 




Figura 1 - Localização e Status das Estações da RBMC em 2014. Fonte: IBGE (2014)

Após realizado o processamento dos arquivos no sitio do NRCAN, visando eliminar os resultados referentes aos arquivos que continham observações com problemas, realizou-se uma filtragem nos resultados obtidos de acordo com os seguintes critérios:

- eliminação dos arquivos que contivessem menos de 50\% de observações no período de vinte quatro horas, que correspondeu a $1,66 \%$ do total dos arquivos processados;

- eliminação dos arquivos nos quais o percentual de observações rejeitadas no processamento ultrapassasse a $50 \%$, que correspondeu a $2,86 \%$ do total dos arquivos processados;

- eliminação dos arquivos nos quais o desvio padrão das coordenadas X, Y e Z fosse superior a $0,030 \mathrm{~m}$ e na altura elipsoidal superior a $0,040 \mathrm{~m}$, resultando na rejeição somada de $2,70 \%$.

Considerando que um mesmo arquivo poderia ser rejeitado por mais de um dos critérios acima mencionados, a rejeição total do conjunto de arquivos foi de 5.994, o que corresponde a um percentual de 3,41\% sobre os 175.740 arquivos processados.

Filtrados os arquivos, os resultados do processamento relativos a cada uma das noventa e cinco estações componentes da RBMC foram reunidos em planilhas Excel (uma para cada estação).

Considerando que o processamento do NRCAN passou a fornecer coordenadas UTM a partir de meados de 2007, optou-se por recalculá-las em todo o período de processamento a partir das coordenadas cartesianas $\mathrm{X}, \mathrm{Y}$ e $\mathrm{Z}$, transformando-as em latitude, longitude e altura elipsoidal (h) e, destas, para UTM em norte (N) e leste (E).

Antecedendo a elaboração dos gráficos, é importante registrar que durante o período de observações (de 2002 a 2013) ocorreram duas mudanças no ITRF, adotadas pelo NRCAN nas datas de 05.11.2006 (ITRF2000 para ITRF2005) e 17.04.2011 (ITRF2005 para ITRF2008), incorrendo na necessidade de serem corrigidas as coordenadas $\mathrm{X}, \mathrm{Y}$ e $\mathrm{Z}$ para transformá-las para o ITRF2000, referência do SIRGAS2000.
De posse das coordenadas cartesianas (X, Y, e Z) fornecidas pelo NRCAN e das coordenadas UTM calculadas, todas foram devidamente corrigidas tanto em função da mudança do ITRF quanto da não consideração da antena; assim sendo, foi possível elaborar, para cada estação da RBMC, os respectivos gráficos relacionando as coordenadas com a variável tempo.

Como exemplo, são mostrados nas Figs. 2 a 8 , os gráficos gerados relativos à estação de Brasília (BRAZ):

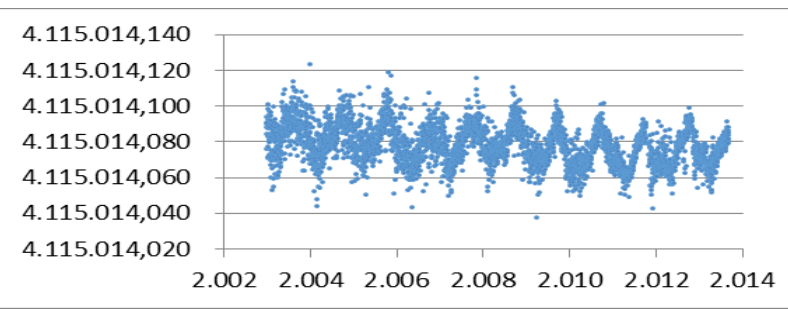

Figura 2 - Evolução da coordenada $\mathrm{X}$ referente à estação de Brasília.

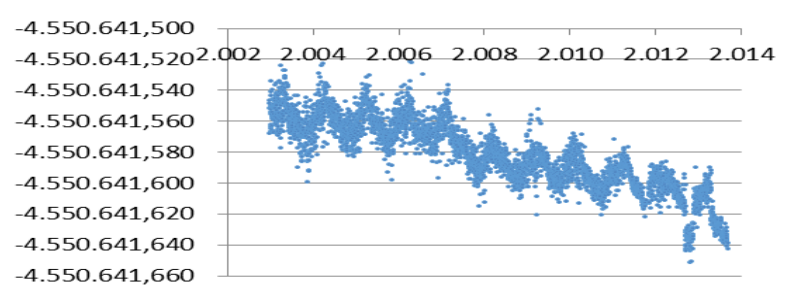

Figura Erro! Nenhum texto com o estilo especificado foi encontrado no documento. - Evolução da coordenada Y referente à estação de Brasília.

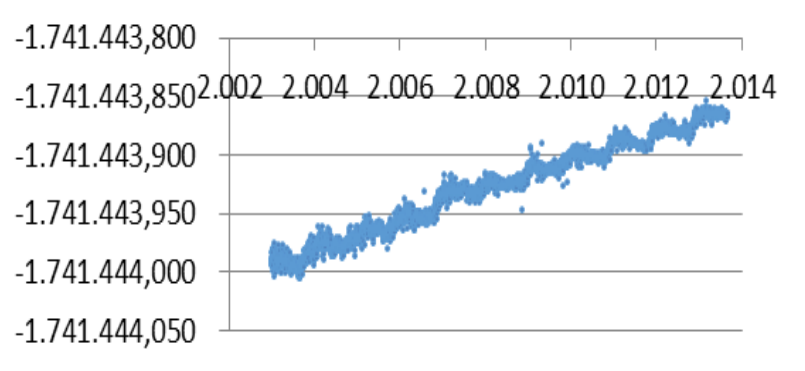

Figura 4 - Evolução da coordenada $\mathrm{Z}$ referente à estação de Brasília.

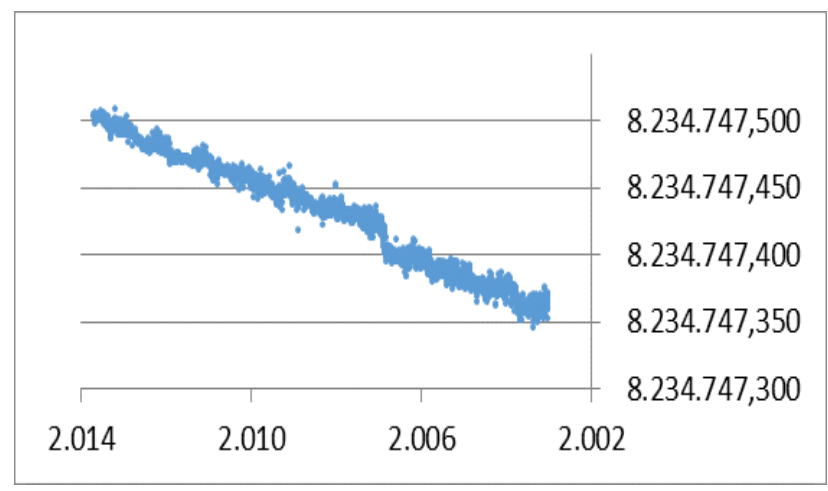

Figura 5 - Evolução da coordenada UTM norte referente à estação de Brasília. 


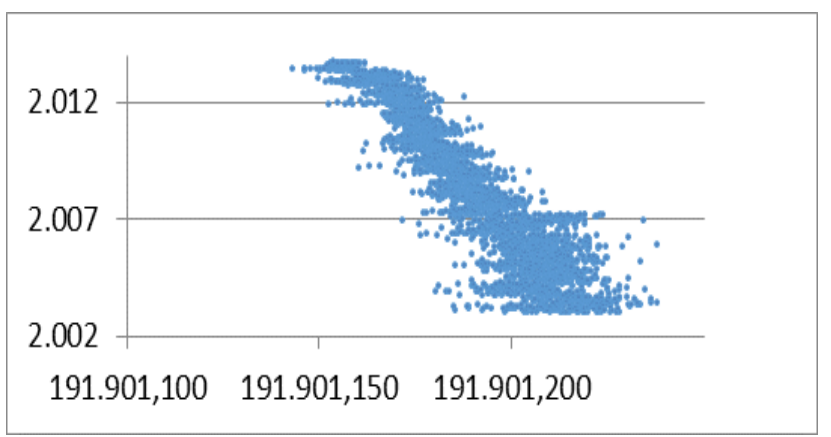

Figura 6 - Evolução da coordenada UTM leste referente à estação de Brasília.

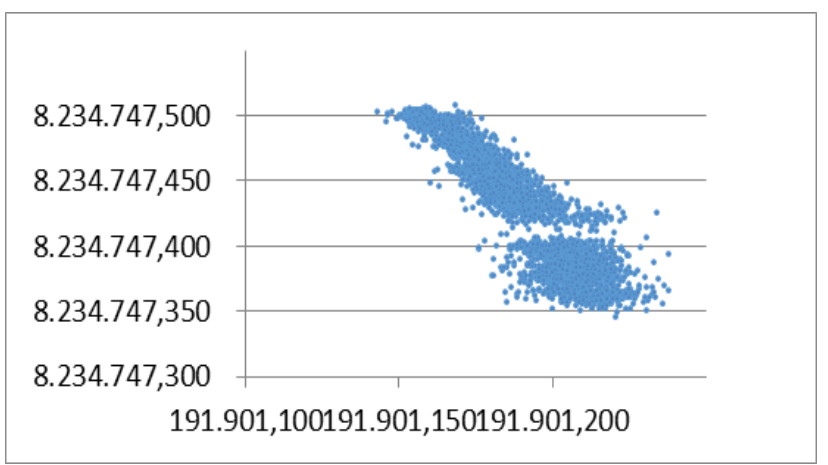

Figura 7 - Deslocamento planimétrico referente à estação de Brasília.

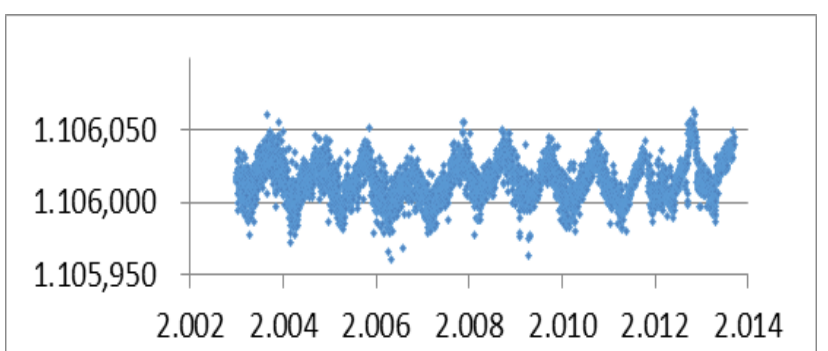

Figura 8 - Evolução da altura elipsoidal referente à estação de Brasília.

Observando-se os gráficos correspondentes às coordenadas cartesianas $\mathrm{X}, \mathrm{Y}$ e $\mathrm{Y}$ bem como a altura elipsoidal - esta com maior ênfase - verifica-se um certo padrão de variação cíclica, associada a uma amplitude próxima ao período de um ano, comportamento este que será objeto de análise em tópicos posteriores. Já as coordenadas planas UTM, norte e leste, possuem uma tendência de variação linear ao longo de todo o período analisado.

Considerando que no longo prazo o comportamento da variação dos valores das coordenadas cartesianas pode ser considerado linear, foi estimado a equação da reta para cada série temporal $(\mathrm{X}, \mathrm{Y}, \mathrm{Z})$ por meio do ajustamento de observações pelo método paramétrico de todas as 95 estações observadas, obtendo-se seus valores para a época 2000.4; na comparação com as coordenadas oficiais do IBGE, verificou-se que em 76 delas ( $80 \%$ do total) as diferenças entre as coordenadas oficiais do IBGE e as calculadas pelo PPP apresentam valores máximos de 3,0 $\mathrm{cm}$, enquanto que em relação às coordenadas UTM o número passa para 90 (95\% do total das estações), o que já era esperado, pois a acurácia do GPS é maior nas componentes planimétricas quando comparada com a componente vertical, devido à distribuição dos satélites.

Utilizando-se dos dados diários coletados nas estações e processados pelo NRCan, foram calculadas as velocidades de deslocamento - em metros/ano - em relação às coordenada $\mathrm{X}, \mathrm{Y}, \mathrm{Z}$ bem como em relação às coordenadas UTM Norte (n) e Leste (e) e da Altura Elipsoidal (u); como era de se esperar, as velocidades das estações em relação aos eixos cartesianos X, Y e Z não mantém uma relação simples entre si, haja visto que são função de uma conjugação entre latitude e longitude e altura elipsoidal de cada ponto.

Considerando que o comportamento dos gráficos em $\mathrm{X}, \mathrm{Y}$ e $\mathrm{Z}$, onde se nota uma oscilação sazonal com amplitude próxima ao período de um ano, conclui-se pela impossibilidade de se considerarem variações lineares para o cálculo das respectivas translações ao longo do tempo, pois, se assim fosse procedido se estariam considerando deslocamentos com características lineares quando, na realidade, eles apresentam uma variação cíclica também significativa.

\subsection{Análise do comportamento dos deslocamentos planimétricos}

Realizado o processamento dos cerca de 170.000 arquivos correspondentes às noventa e cinco estações da RBMC, constatou-se que em todas elas há um deslocamento nas direções norte e oeste; deste conjunto de estações, verificou-se que em Coari (AMCO), Manaus (MANA), Santarém (PAST) e Ubatuba (UBAT) o comportamento apresentou-se destoante das demais.

À exceção de Ubatuba (UBAT), que apresentou problemas cuja(s) causa(s) não foram identificadas mesmo após contato com o IBGE, as outras três possuem como característica comum o fato de possuir um baixo número de dias processados (abaixo de 450), o que poderá se constituir na causa de obtenção de resultados não condizentes com as demais estações.

Utilizando-se dos dados das 91 estações restantes, calcularam-se as médias e desvio-padrão das velocidades registradas, obtendo-se os seguintes valores para as velocidades planimétricas (em $\mathrm{m} / \mathrm{ano}$ ) e seus respectivos desvios padrão:

Tabela 1 - Velocidades planimétricas médias e seus respectivos desvios padrão

\begin{tabular}{l|r|r}
\hline & Norte (n) & \multicolumn{1}{c}{ Leste (e) } \\
\hline Média $\boldsymbol{\mu}$ & 0,0125 & $-0,0040$ \\
\hline Desvio Padrão $\sigma$ & 0,0011 & 0,0013 \\
\hline
\end{tabular}

Considerando os valores obtidos, os mesmos sugerem que a Placa Tectônica da América do Sul, no que diz à sua porção na qual nosso país está inserido, se desloca de uma forma praticamente uniforme à razão de $12,5 \mathrm{~mm} /$ ano para o norte e $4 \mathrm{~mm} /$ ano para oeste, 
apresentando desvios padrão tanto para norte quanto para oeste da ordem de $1,2 \mathrm{~mm}$.

Já no que se refere às velocidade de deslocamento das estações com relação à vertical, ou seja, no sentido da variação da altura elipsoidal, verificou-se que em $95 \%$ das estações o módulo da velocidade da altura elipsoidal é inferior a $5 \mathrm{~mm}$ por ano, sendo da mesma ordem de grandeza o número de estações que se deslocam para cima ou para baixo.

\subsection{Constatação de deslocamentos altimétricos}

Realizados os processamentos dos arquivos correspondentes às noventa e cinco estações componentes da RBMC, conforme já registrado anteriormente, foram elaborados gráficos correspondentes às variações das coordenadas cartesianas $\mathrm{X}, \mathrm{Y}$ e $\mathrm{Z}$ bem como das coordenadas norte e leste e da altura elipsoidal.

Observando-se cada um desses gráficos, constata-se, em praticamente todas as estações, um comportamento cíclico tanto nas coordenadas cartesianas quanto na altura elipsoidal, com amplitude próxima de um ano.

É importante registrar, como já era esperado, que em relação às coordenadas UTM norte e leste não se verifica este comportamento cíclico.

Os efeitos observados nas séries temporais em relação às coordenadas cartesianas $\mathrm{X}, \mathrm{Y}$ e $\mathrm{Z}$ e, por consequência na altura elipsoidal, podem ser modelados mediante o ajustamento de uma função adequada aos respectivos dados (ROSA, 2008).

A escolha do modelo matemático é realizada considerando o conhecimento da variação dos dados. No caso presente, onde foi constatada uma tendência linear associada também a uma variação de característica cíclica, com período de um ano, optou-se por utilizar um modelo matemático adaptado de (NIKOLAIDIS, 2002) para representar a variação da altura elipsoidal, que leve em consideração esses efeitos, conforme apresentado na equação:

$$
h\left(\mathrm{t}_{i}\right)=a+b \mathrm{t}_{i}+c \sin \left(2 \pi \mathrm{t}_{i}\right)+\mathrm{d} \cos \left(2 \pi \mathrm{t}_{i}\right)+v i
$$

onde h representa a altura elipsoidal em cada época ti, $a$ e $b$ representam os coeficientes linear e angular da reta, enquanto que os coeficientes $c$ e $d$ representam a amplitude dos efeitos anuais; e vi que representa os efeitos não modelados, considerados como sendo efeitos residuais.

Com o objetivo de realizar comparativos entre diversas estações e considerando que estações próximas por vezes apresentam comportamento distinto uma das outras, realizou-se o ajustamento para estimar os coeficientes da equação (2) para cada estação e através do programa Excel, com a utilização da equação acima descrita estimada para cada estação fez-se uma rotina para a produção automática de gráficos representativos das variações nas alturas elipsoidais em cada uma das estações escolhidas.
De posse das amplitudes anuais da altura elipsoidal estimadas para cada estação, as mesmas para fins de análises foram classificadas em função dos seus valores de amplitude anual nas seguintes categorias:

- Planas (até 10 mm) - 16 estações;

- $\quad$ Baixa (de 11 a 16 mm) - 18 estações;

- $\quad$ Média (de 17 a 23 mm) - 32 estações;

- Média Alta (de 24 a 28 mm) - 11 estações;

- Alta (de 29 a 37 mm) - 11 estações;

- Muito Alta (acima de 38 mm) - 6 estações.

No intuito de melhor representar as estações associadas às suas respectivas amplitudes, elaborou-se a figura a seguir, onde as mesmas foram classificadas em função da amplitude anual da variação de suas alturas elipsoidais, sendo plotadas em função de suas latitudes e longitudes.

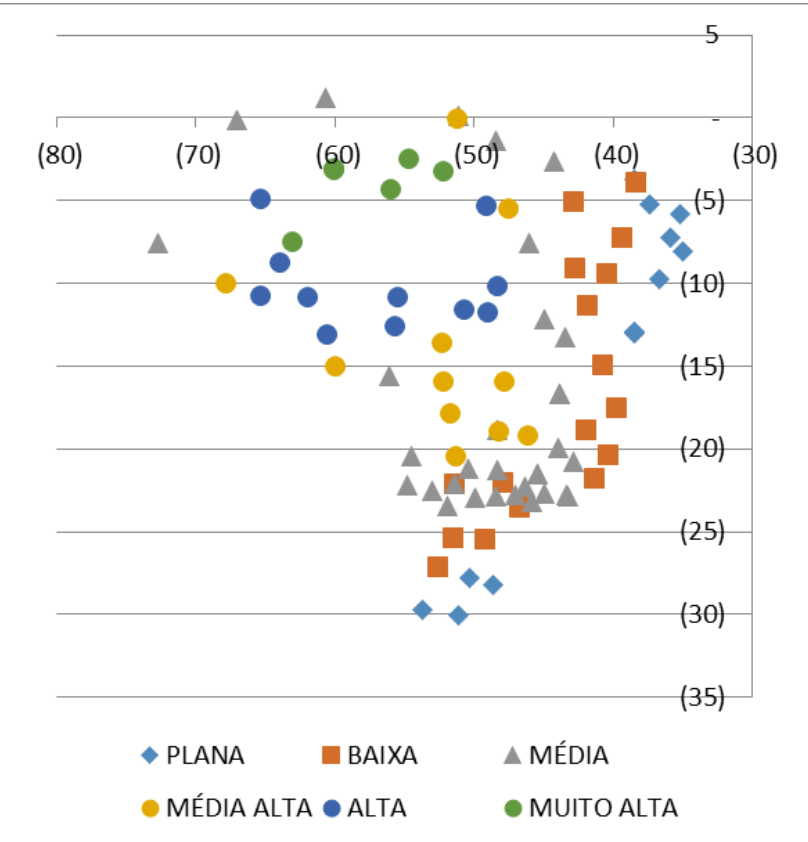

Figura 9 - Representação das estações classificadas pela amplitude da oscilação vertical

Analisando-se a figura acima, podemos concluir que no extremo sul do país e no litoral nordestino as amplitudes anuais registradas são menores que $10 \mathrm{~mm}$, amplitude esta que cresce em direção ao interior do nordeste, parte do litoral leste (Bahia e Espírito Santo) e algumas regiões de São Paulo e Paraná, registrando amplitudes de até $16 \mathrm{~mm}$.

As amplitudes apresentam crescimento em direção ao interior do país, principalmente em São Paulo, Mato Grosso do Sul e Bahia bem como na fronteira noroeste do país, apresentando valores entre 17 e $23 \mathrm{~mm}$.

$\mathrm{Na}$ região centro-oeste e alguns pontos esparsos, a amplitude pode atingir $28 \mathrm{~mm}$.

$\mathrm{Na}$ região amazônica ocorrem os valores mais elevados de amplitude anual, atingindo até $71 \mathrm{~mm}$, o que pode ser explicado, em parte, pelo regime hidrológico típico da região, onde registram-se grandes inundações e 
estiagens; nessa região verificou-se que as oscilações dos níveis constatadas no processamento estão coerentes com as épocas de inundações e estiagens registradas nos dados da Agência Nacional de Águas (ANA). Estes resultados já foram verificados em outras pesquisas, como exemplo, Rosa (2008).

Visando estabelecer uma comparação entre amplitudes anuais registradas nas estações da RBMC, desenvolveu-se, numa planilha excel, uma macro que possibilita a representação simultânea das amplitudes anuais registradas em um grupo de até seis estações, incluindo a estação escolhida bem como outras cinco que lhes são próximas.

Assim sendo, como exemplo, no gráfico da Figura 10, estão representadas as amplitudes anuais da estação de Brasília (BRAZ) bem como das outras cinco que lhes são mais próximas, a saber: Uberlândia (UBER e MGUB), Rio Parnaíba (MGRP) e Montes Claros (MCLA e MGMC); em todas elas a amplitude anual situa-se entre 18 e $24 \mathrm{~mm}$.

Através da representação, nota-se que as maiores elevações e depressões situam-se em períodos próximos aos equinócios enquanto que nos solstícios, tanto de verão quanto de inverno, os valores da amplitude situam-se próximos da média anual.

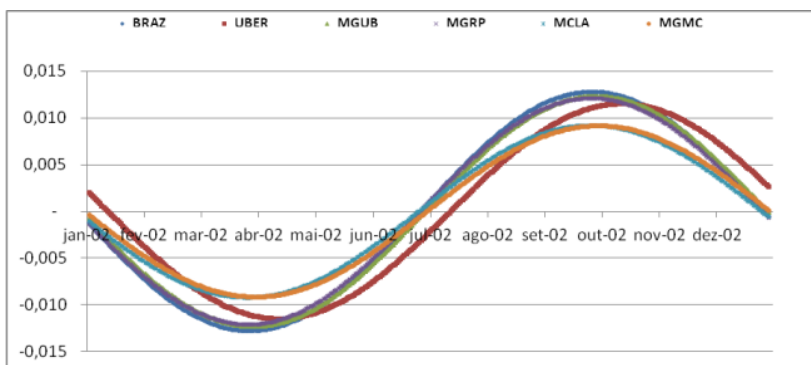

Figura 10 - Oscilação vertical de estações mais próximas a Brasília

\subsection{Considerações sobre maré terrestre e oceânica}

As marés funcionam como ondas de baixa profundidade, já que apresentam comprimentos de onda de milhares de quilômetros e alturas que chegam a atingir a ordem de quinze metros.

As marés terrestres são produzidas pela atração gravitacional do Sol e da Lua. Como é sabido, segundo a lei de Newton, essa atração é diretamente proporcional às massas e inversamente proporcional ao quadrado da distância. Porém, no processo gerador de marés, a proporcionalidade refere-se ao cubo da distância.

Devido a esse fato e uma vez que a Lua está muito mais próxima da Terra que o Sol, a força geradora das marés por parte do Sol é igual a $46 \%$ da força da Lua.

A Terra e a Lua formam um conjunto que gira em torno do Sol. Nesse movimento de translação o conjunto Terra-Lua é representado pelo centro comum de gravidade que situa-se dentro do manto terrestre, a 4.700 km de distância do centro da Terra.

É este centro que descreve uma órbita elíptica em relação ao Sol, enquanto que a Terra e a Lua descrevem órbitas mais complexas e relativamente sinuosas.
Todos as partículas pertencentes à Terra descrevem círculos de raios iguais, à volta desse centro. A força centrípeta requerida por todas as partículas da Terra para as manter em rotação é igual em todos os pontos da Terra. Porém, a força da gravidade exercida pela Lua varia consoante a posição de cada ponto terrestre em relação à Lua. Da subtração dos vetores da força centrípeta e da força gravitacional resulta num outro vetor, que corresponde à força das marés.

Através da análise dos resultados do processamento dos dados, verifica-se que o fenômeno da maré terrestre não é detectado.

Em contato com o Serviço Canadense verificou-se que não seria possível configurar o processamento em função da consideração ou não de modelos de maré terrestre, de forma que não foi possível estabelecer formas para corrigir os resultados em função deste fenômeno.

Já em relação à maré oceânica, que em nosso país é mais significativa no litoral das regiões norte e nordeste, realizou-se uma análise na estação da RBMC de São Luís - SALU.

Inicialmente, através da tabela de marés, determinaram-se, em cada mês do ano de 2012, o dia em que se verificaram as maiores amplitudes de maré oceânica na região de São Luís, capital do Estado do Maranhão.

Em cada mês do ano, a partir de janeiro, os dias considerados foram 24, 22, 10, 7, 7, 4, 4, 3, 1, 16,15 e 15 de dezembro.

Nestes dias processaram-se os dados da estação obtendo-se, através do arquivo gerado do tipo .pos, a cada quinze segundos e ao longo do período de vinte e quatro horas, as alturas elipsoidais da estação (em metros), conforme mostrado na Fig. 11 que representa as alturas elipsoidais a partir da estabilização que ocorreu a partir da quarta hora do dia.

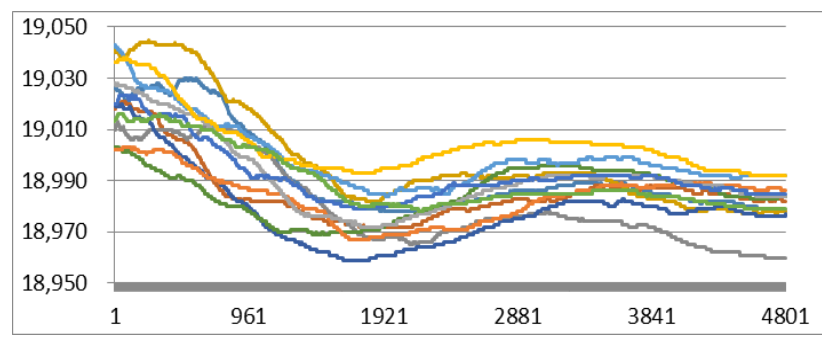

Figura 11 - Oscilação da altura elipsoidal (em metros) da estação de São Luís para análise da ocorrência da maré oceânica.

Da análise do gráfico representativo das alturas elipsoidais relativas a doze dias do ano de 2012 (em cada mês o dia em que ocorreu a maior amplitude de maré) onde no eixo vertical está representada a altura elipsoidal da estação e no eixo horizontal os intervalos de tempo a cada quinze segundos, pode-se constatar que a maré oceânica influencia na variação da altura elipsoidal da estação, apresentando uma amplitude da ordem de $0,100 \mathrm{~m}$ 
Procedimento semelhante foi adotado na estação da RBMC de Brasília - BRAZ, distante cerca de $950 \mathrm{~km}$ do litoral brasileiro. Neste caso, a variação da altura elipsoidal foi insignificante, como se pode verificar no gráfico da Figura 12, que representa as alturas elipsoidais a partir da estabilização que ocorreu por volta da oitava hora do dia, não mantendo nenhuma relação com a variação do nível do oceano, com o que se pode inferir que, neste caso, a maré oceânica não influi na altura elipsoidal da estação.

Interessante ressaltar que as amplitudes das alturas elipsoidais ao longo do período de um ano nas duas estações consideradas, estão compatíveis com os valores calculados no processamento das 95 estações da RBMC.

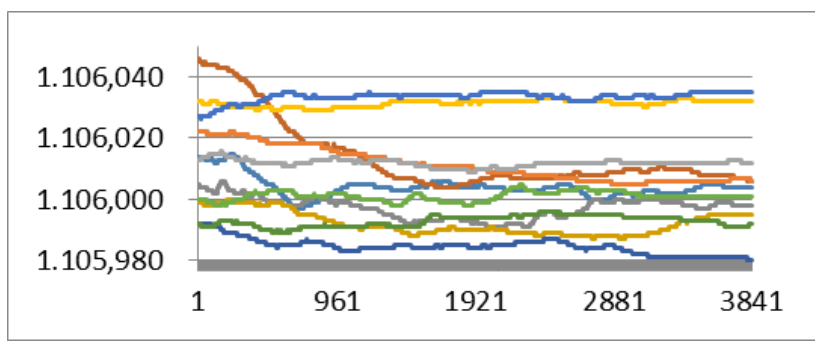

Figura 12 - Oscilação altura elipsoidal (em metros) da estação de Brasília para análise da ocorrência da maré oceânica

Uma análise mais apurada da influência da maré oceânica sobre a altura elipsoidal de pontos situados sobre a placa tectônica poderia ser objeto de estudos futuros, onde se procuraria estabelecer uma relação entre a variação da altura elipsoidal com a composição das rochas formadoras das referidas placas.

\subsection{Elaboração dos Modelos}

Com base nos resultados obtidos no processamento de dados das estações da RBMC foram desenvolvidas planilhas para determinar as velocidades de deslocamento da Placa Tectônica da América do Sul em qualquer ponto localizado em território brasileiro referentes as coordenadas norte, leste e altura elipsoidal, a saber:

\subsubsection{Estabelecimento de Modelo de Deslocamento da Placa Tectônica}

Após realizada uma minuciosa análise dos deslocamentos planimétricos e altimétricos das estações da RBMC, conclui-se que há uma certa uniformidade nos deslocamentos nos sentidos norte e oeste, da ordem de 12,5 e 4,0 mm/ano, respectivamente, com desvio-padrão de $1,1 \mathrm{~mm}$ e $1,3 \mathrm{~mm}$, enquanto que na vertical predominam os deslocamentos cíclicos que apresentam periodicidade de um ano com amplitudes de até $71 \mathrm{~mm}$, sendo que os deslocamentos lineares no longo prazo variam de -4,9 mm/ano a 5,6 mm/ano, situando-se a média das noventa e cinco estações em $0,1 \mathrm{~mm} /$ ano com desvio padrão de $3,2 \mathrm{~mm}$.
No que se refere às coordenadas cartesianas X, Y e $\mathrm{Z}$, constatou-se em todas as estações analisadas, um comportamento cíclico com amplitude anual, causada pela oscilação da altura elipsoidal em torno de um valor que sofre variação de característica linear ao longo do tempo.

Feitas essas considerações, conclui-se que não é correto calcularem-se velocidades de deslocamentos lineares em X, Y e Z, pois suas variações são cíclicas, e a adoção de modelos lineares para suas velocidades certamente implicariam em erros consideráveis

Tendo presente as velocidades de deslocamento nos sentidos norte e oeste bem como na altura elipsoidal de todas as estações da RBMC, onde se constatou que havia inconsistências em quatro estações (Coari, Manaus, Santarém e Ubatuba), elaborou-se uma planilha excel que considera como dados de entrada as coordenadas cartesianas X, Y e Z, resultando na determinação das velocidades de deslocamento nas direções norte e oeste e altura elipsoidal, associadas aos seus respectivos desviopadrão.

A seguir é representada a tela da planilha em excel onde se informam as coordenadas cartesianas $\mathrm{X}, \mathrm{Y}$ e $\mathrm{Z}$ processadas pelo PPP, tendo com resultado as velocidades calculadas em Norte (n), Leste (e) e Altura Elipsoidal (u).

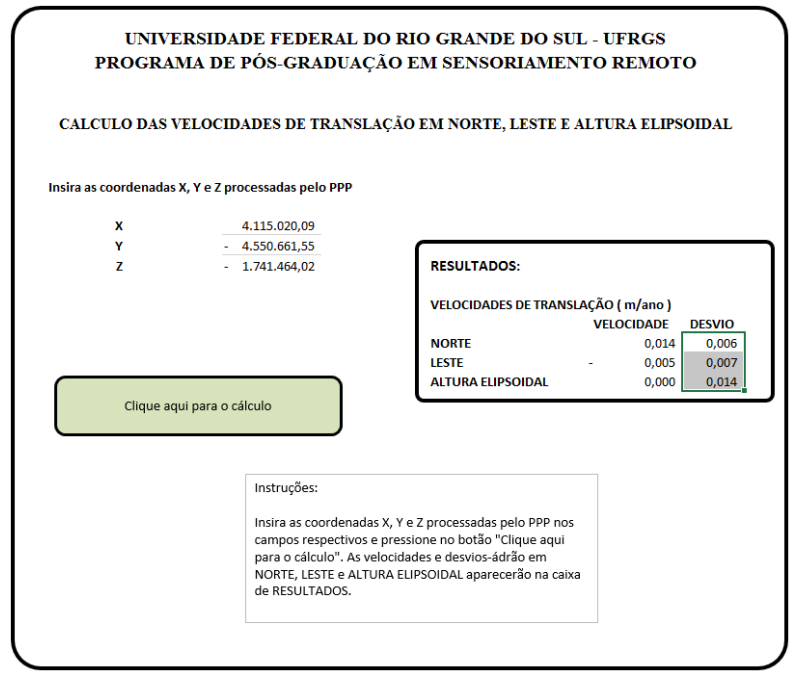

Figura 13 - Tela da planilha Excel que calcula Velocidades de Translação em Norte, Leste e Altura Elipsoidal.

No que diz respeito à altura elipsoidal, como já referido anteriormente, verificou-se haver uma variação cíclica sazonal, com período de um ano, e amplitudes que atingem até $71 \mathrm{~mm}$ na região amazônica.

\subsubsection{Determinação de coordenadas transformadas norte (n), leste (e) e altura elipsoidal (u) para a época de referência do SIRGAS2000}

Considerando que o processamento realizado pelo PPP fornece o resultado referido à época da coleta dos dados e que, via de regra, é necessário conhecerem-se as 
coordenadas numa outra época, é de suma importância que se possua uma forma para transformá-las.

Assim sendo, foi desenvolvida uma planilha em Excel, que permite esta correção, cuja tela está representada a seguir, onde se informam as coordenadas cartesianas X, Y e Z processadas pelo PPP, bem como a data da coleta dos dados, tendo com resultado as coordenadas calculadas em Norte (n), Leste (e) bem como Altura Elipsoidal (u), associadas aos seus respectivos desvios-padrão.

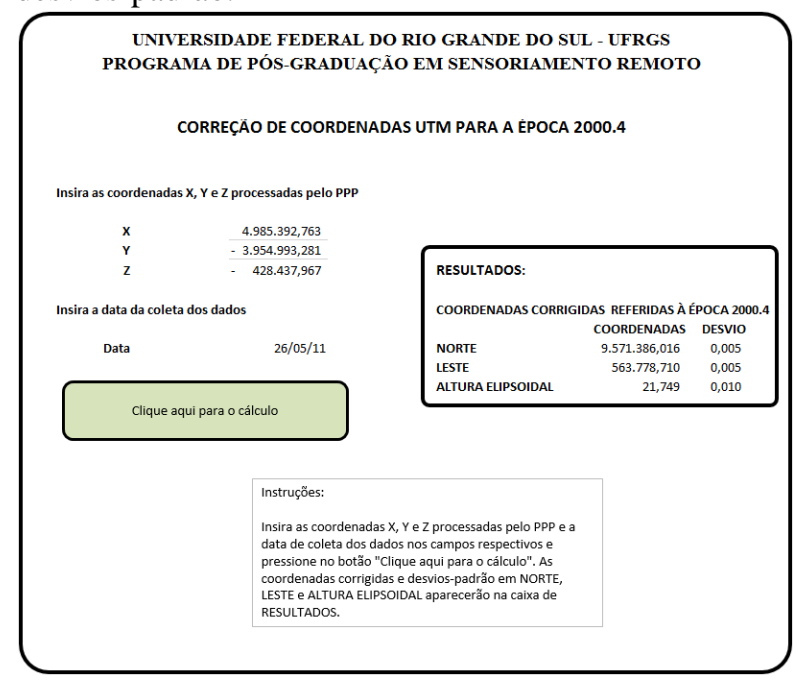

Figura 14 - Tela da planilha Excel que calcula Coordenadas UTM e Altura Elipsoidal.

Para tanto é fundamental que se possuam pontos distribuídos da melhor forma possível ao longo da área em que se deseja realizar as correções, tendo sido utilizadas noventa e uma estações da RBMC.

Considerando a existência de uma variação cíclica na altura elipsoidal, elaboraram-se curvas de variação anual para cada uma das estações, o que nos permite calcular a variação diária em relação a 2000,4 época referência do SIRGAS2000.

Tanto as velocidades lineares (em norte, leste e altura elipsoidal) quanto as variações cíclicas (em altura elipsoidal) estimadas para todas as estações utilizadas são os dados utilizados pelo programa desenvolvido e cuja tela foi apresentada na Fig. 14.

Interessados em obter os programas desenvolvidos podem entrar em contato com os autores.

\section{CONCLUSÕES E RECOMENDAÇÕES}

Considerando que o objetivo deste trabalho se constituiu no estudo do deslocamento da Placa Tectônica da América do Sul, particularmente de sua porção localizada em território brasileiro, visando determinar suas velocidades de deslocamento no sistema cartesiano $\mathrm{X}, \mathrm{Y}$ e Z, bem como no plano horizontal (planimétrico) analisando o comportamento de seus deslocamentos verticais, mediante a utilização do processamento de dados GPS realizados através do Método de Processamento por Ponto Preciso - PPP, pode-se afirmar que o mesmo foi cumprido, na medida em que foi estabelecido um modelo de deslocamento da Placa Tectônica e desenvolvido um software para a transformação de coordenadas tanto planimétricas (UTM) quanto altimétricas entre duas épocas distintas, sendo uma delas a de obtenção de dados e a outra referente à da época do SIRGAS2000.

Após processados mais de 170.000 arquivos de dados obtidos num período superior a onze anos entre 2002 e 2013, abrangendo todas as estações ativas da RBMC, pode-se concluir que o comportamento das coordenadas cartesianas $\mathrm{X}, \mathrm{Y}$ e $\mathrm{Z}$ em praticamente todas as estações é de natureza linear e cíclica, com amplitude da ordem de um ano.

Face à natureza deste comportamento cíclico, tornase desaconselhável utilizarem-se velocidades lineares e constantes para o cálculo das correções das coordenadas $\mathrm{X}, \mathrm{Y}$ e $\mathrm{Z}$, pois isto causaria a obtenção de resultados pouco precisos na transformação de coordenadas entre duas épocas distintas.

Assim sendo, após transformarem-se as coordenadas cartesianas X, Y e Z em coordenadas planas UTM (norte e leste) e altura elipsoidal, constatou-se que a variação das coordenadas ao longo do tempo, tanto em norte quanto em leste, têm um comportamento linear, sendo possível e adequada a adoção de um valor fixo para ambas as velocidades de translação.

Já em relação à altura elipsoidal, seu comportamento de variação é cíclico, apresentando um período anual, com amplitudes variando entre $3 \mathrm{~mm}$, registrada em Porto Alegre e $71 \mathrm{~mm}$ medida em Manaus. Este comportamento é o responsável pela variação cíclica verificada nas coordenadas cartesianas $\mathrm{X}, \mathrm{Y}$ e Z .

Finalmente, foi possível realizar a correção da altura elipsoidal de cada estação da RBMC em função do dia do ano em que foi realizada a coleta dos dados tendo em vista o conhecimento de seu comportamento cíclico, possibilitando a transformação de sua coordenada entre duas épocas distintas.

Considerando a experiência adquirida ao longo do desenvolvimento do trabalho, como sugestões para trabalhos futuros, recomenda-se: realizar o processamento de dados das estações da RBMC a partir de setembro de 2013 (mês até onde se processaram informações para elaboração deste artigo); aplicar, sobre o resultado obtido no processamento desses dados, o software desenvolvido neste artigo, no intuito de verificar se os resultados obtidos correspondem às coordenadas conhecidas para a época 2000.4; realizar estudos para encontrar, além da concentração de massas d' água na região amazônica, eventuais causas que expliquem as variações cíclicas registradas nas alturas elipsoidais nas estações da RBMC e, por consequência, em todo o território brasileiro.

Dentro desta linha, tentar verificar se parte das variações na altura elipsoidal são decorrência de erros que não foram considerados pelo PPP, como exemplo, os erros de segunda e terceira ordem da ionosfera.

Finalmente, conectar, através do programa TEQC, em grupos de cinco arquivos sequenciais no formato RINEX, gerados pelo IBGE para cada uma das estações 
da RBMC (por exemplo: o primeiro arquivo contemplaria os dias 1, 2, 3, 4 e 5 de um determinado ano; o segundo os dias 2, 3, 4, 5 e 6 do mesmo ano e assim sucessivamente), para serem processados pelo NRCan, a assim obtendo novas coordenadas referidas a 2000.4, bem como novos valores de velocidades em X, Y, Z, n, e e u, e modelos de variação cíclica da altura elipsoidal em cada estação, que seriam comparadas com os resultados obtidos neste trabalho.

\section{AGRADECIMENTOS}

Ao NRCan - Natural Resources Canada, que possibilitou o processamento gratuito, através de seu sítio, de mais de 170.000 arquivos de dados GPS. Ao IBGE pelos dados gratuitos da RBMC. Ao CNPq pelo apoio financeiro via Bolsa Produtividade em Pesquisa e Projeto Universal do segundo autor.

\section{REFERÊNCIAS BIBLIOGRÁFICAS}

ABREU, M. A.; FONSECA JUNIOR, E. S. 2005. Comparação de ferramentas on-line para processamento de dados GPS. In: COLÓQUIO BRASILEIRO DE CIÊNCIAS GEODÉSICAS, 4, Curitiba, Anais (CD-ROM-CBCG), p. 1-6.

DING, X. L. et al. Seasonal and secular positional variations at eight co-located GPS and VLBI statioms, v.79, Journal of Geodesy, p71-81, 2005.

FORTES L. P., Operacionalização da rede Brasileira de Monitoramento Contínuo do Sistema GPS (RBMC). Dissertação de Mestrado. IME. 152p, 1997.

FREIBERGER Jr. J. et al.; Calibração de Antenas GPS em diferentes Estações. Bol. Cienc. Geod. Curitiba, v.11 n.2 p.157-77, jul-dez., 2005.

HÉROUX, P., KOUBA, J. GPS Precise Point Positioning with a difference. http:// www.geod.emr.ca/docs/PDF $12 \mathrm{p}, 1995$.

HOFMANN-WELLENHOF et al. 2008; GNSS - Global Navigation Satellite System: GPS, GLONASS, GALILEO, and more. Áustria, Springer Wien New York, $516 \mathrm{p}$.

IBGE RBMC - Rede Brasileira de Monitoramento Contínuo dos Sistemas GNSS. 2014. Disponível em: <http://www.ibge.gov.br/home/geociencias/geodesia/r bmc/rbmc.shtm?c=7>. Acesso em: 12/10/2014.

IGS (INTERNATIONAL GNSS SERVICE). 2008. IGS Products. Disponível em: http://igscb.jpl.nasa.gov/components/prods.html, acesso em: 28/12/2014.

LAHAYE, F. et al.; Online Precise Point Positioning: a new, timely service from Natural Resources Canada. GPSWORLD, 2008. (Innovation), 1:1-5. Disponível em: http://sidt.gpsworld.com/ gpssidt/article/article Detail.jsp id $=549570 \&$ sk $=\&$ date $=\&$ pageID $=9$, acesso em: 20/02/2012.
LEICK, A. 2004. GPS Satellite Surveying. $3^{\text {a }}$ ed., New Jersey, John Wiley \& Sons, 435 p.

MADER, G. A comparison of absolute and relative GPS Antenna Calibrations, 2001. GPS Solution. V. 4, n 4, p37-40, 2001.

MONICO, J. F. G. et al.; Confiabilidade interna e externa em Aplicações Geodésicas: Exemplo de uma Rede de Nivelamento. Geodésia Online, v. 2, p. 1, 2006.

MONICO, J. F. G. Posicionamento pelo GNSS: descrição, fundamentos e aplicações. 2. ed. São Paulo: Ed. UNESP, 2008. 473p.

MONICO, J. F. G. et al.; Acurácia e precisão: revendo os conceitos de forma acurada. Boletim de Ciências Geodésicas, v. 15, n. 3, p. 469-483, 2009.

NIKOLAIDIS, R. Observation of geodetic an seismic deformation with the Global Positioning System. Tese de Doutorado. University of California, 2002.

NRCAN (NATURAL RESOURCE CANADA). 2004. CSRS-PPP - User Guide. Geodetic Survey of Canada. Canadian Spatial Reference System, Geodetic Survey Canada. Disponível em: http://198.103.48.76/userguide/pdf/howtouse.pdf, acesso em: 20/02/2012.

NRCAN (NATURAL RESOURCE CANADA). 2009. CSRS-PPP an online Global GPS Processing Service. Canadian Spatial Reference System, Geodetic Survey Canada. Disponível em http://www.geod.nrcan.gc.ca/productsproduits/index_e.php, acesso em: 20/02/2012.

PEREZ, J. A. S. et al.; Velocity Field Estimation Using GPS Precise Point Positioning: The South American Plate Case. Journal of Global Positioning Systems, 2(2):90-99

ROSA, G.P.S. 2008. Análise de Séries Temporais de Coordenadas Estimadas com GPS: Uma proposta metodológica para eliminação de efeitos sazonais. Presidente Prudente, Universidade Estadual Paulista, Dissertação de Mestrado, 106 p.

SEEBER, G. Satellite Geodesy: Foundations, methods, and applications. 2.ed. New York: Walter de Gruyter, 2003.

WITCHAYANGKOON, B. 2000. Elements of GPS Precise Point Positioning. Orono, ME, University of Maine, Tese de PhD, 265 p.

WUEBBENA G. et al.; A New Approach for Field Calibration of Absolute Antenna Phase Center Variation. NAVIGATION, Journal of the Institute of Navigation Summer, 1997 v. 44, n.2.

ZUMBERGE J. B., BERTIGER W. I., Ephemeris and Clock Navigation Message Accuracy, In PARKINSON, B. W.; SPILKER, J. J., Global Positioning System: Theory and Applications, v.1, Cambidge, American Institute of Aeronautics and astronautics , p.585-600, 1996. 